\title{
Trends of Gestational Trophoblastic Disease at a Tertiary Care Hospital
}

\author{
Shakya $\mathbf{B}^{1}$, Baral $\mathbf{G}^{2}$ \\ ${ }^{1}$ Chhetrapati Family Welfare Center, Kathmandu, Nepal, ${ }^{2}$ Paropakar Maternity and Women's Hospital, Thapathali
}

Received: 9-May-2017; Accepted: 30-May-2017

Aims: The objective of this study was to determine the clinical presentation of GTD and response of GTN to single and multiple agent chemotherapy on the basis of WHO Prognostic risk scoring system.

Methods: This was a cross-sectional retrospective study undertaken at Paropakar Maternity and Women's Hospital. The medical records of 102 GTD cases were reviewed from January 25, 2015 to January 24, 2016. Data pertaining patient characteristics, histopathology types of GTD, management, prognostic risk scores, chemotherapy, follow up and remissions were retrieved and were analyzed using SPSS version 16.0.

Results: Among 102 GTD cases, the most common presentation was vaginal bleeding $69(67.6 \%)$ followed by ultrasound diagnosed cases 30(29.4\%). Primary management of all cases were suction evacuation, 68 completed and 12 are under follow-up. GTN was diagnosed in $14 / 90(15.5 \%)$ of complete mole and 5/90 (5.5\%) of partial mole. Twenty-two cases received chemotherapy for persistent gestational trophoblastic tumour(19) and invasive mole(3). Twenty cases were low risk score group and two cases under high risk group. Out of 20 low risk cases that received MTX-FA, 13/20 (65\%) achieved remission. Due to low response of MTX-FA, five of them were converted to Actinomycin-D and achieved remission( $(100 \%)$. Two high risk cases received EMA-CO regimen and achieved $100 \%$ remission. Two low risk GTN, complete and invasive mole (underwent hysterectomy) are undergoing MTX-FA chemotherapy.

Conclusions: The most common presentation of GTD was vaginal bleeding. Low risk GTN achieved $65 \%$ remission with Methotrexate-Folinic acid, ultimately achieved 100\% remission with Actinomycin-D. High risk GTN achieved $100 \%$ remission with EMA-CO regimen.

Keywords: Actinomycin-D; EMA-CO; gestational trophoblastic disease; gestational trophoblastic neoplasia; Methotrexate-Folinic acid; remission.

DOI: http://dx.doi.org/10.3126/njog.v12i1.18977

\section{INTRODUCTION}

Gestational trophoblastic disease (GTD) describes a rare and highly curable group of tumour pathology that arises from tissues of placental origin and results from abnormal conception caused by aberrant fertilization. ${ }^{1}$ Most of the GTD cases include two types of hydatidiform moles (HM) that have a variable potential to progress into the rare malignant disease gestational trophoblastic neoplasia $(\mathrm{GTN}))^{2,3}$ GTN is among rare human tumours that can be cured, with an overall $90 \%$ of patient survival, due to the inherent chemotherapy sensitivity of trophoblastic neoplasms, the effective use of the tumour marker beta human chorionic gonadotrophin ( $\beta \mathrm{hCG}$ ) for diagnosis of disease and monitoring of therapy and the identification of prognostic factors that enhances individualization of chemotherapy. ${ }^{1-7}$

\section{CORRESPONDENCE}

Dr Beemba Shakya, Chhetrapati Family Welfare Center, Chhetrapati, Kathmandu;

Email: docbeemba@yahoo.com;

Phone: +977-9841 729847
The objective of this study was to determine the clinical presentation of GTD and response of GTN to single and multiple agent chemotherapy on the basis of WHO Prognostic risk scoring system.

\section{METHODS}

This was a cross-sectional retrospective study undertaken at Paropakar Maternity and Women's Hospital (PMWH). Ethical approval was taken from the hospital. The medical records of GTD were reviewed from January 25, 2015 to January 24, 2016. The charts were collected from medical record section. Data pertaining patient characteristics, histopathology types of GTD, management, prognostic risk scores, chemotherapy, follow up and remissions were retrieved and were analyzed using SPSS version 16.0.

Following suction evacuation, patients were followed up with weekly serum $\beta$ hCG till three consecutive normal values, then monthly for six months.

For malignant and persistent gestational trophoblastic tumours (PGTT), WHO Prognostic Scoring System based on prognostic factors was done. (Table 1) 
Table 1. Modified WHO Prognostic Scoring System as Adapted by FIGO. ${ }^{8}$

\begin{tabular}{|lllll|}
\hline Risk factor & Score of 0 & Score of 1 & Score of 2 & Score of 4 \\
\hline Age & $<40 \mathrm{y}$ & $\geq 40 \mathrm{y}$ & - & - \\
Antecedent pregnancy & Mole & Abortion & Term & - \\
Interval months from index pregnancy & $<4$ & $4-6$ & $7-12$ & $>12$ \\
Pretreatment serum hCG level & $<10^{3}$ & $10^{3}-10^{4}$ & $10^{4}-10^{5}$ & $>10^{5}$ \\
Largest tumor size (including uterus) & $<3 \mathrm{~cm}$ & $3-4 \mathrm{~cm}$ & $\geq 5 \mathrm{~cm}$ & - \\
Site of metastases & Lung & Spleen, kidney & Gastrointestinal system & Liver, brain \\
Number of metastases & - & $1-4$ & $5-8$ & $>8$ \\
Previous failed chemotherapy & - & - & Single drug & $\geq 2$ drugs \\
\hline
\end{tabular}

For low risk $\leq 6$ score, Methotrexate (MTX) $50 \mathrm{mg}$ intramuscular $(\mathrm{I} / \mathrm{M})$ on days $(1,3,5,7)$ with folinic acid (FA) $7.5 \mathrm{mg} \mathrm{I} / \mathrm{M}$ on days $2,4,6,8$ was administered. For low response cases, it was converted into Actinomycin-D (Act-D) $12 \mathrm{mcg} / \mathrm{kg}$ intravenous (I/V) everyday for 5 days. For high risk $\geq 7$ score, multiagent chemotherapy EMA-CO regimen was used. Etoposide, MTX, Act-D (EMA) on days 1 and 2 and Cyclphosphamide and Vincristine (CO) on day 8 was administered.

\section{Course 1: EMA}

Day 1

Etoposide $100 \mathrm{mg} / \mathrm{m}^{2} \mathrm{I} / \mathrm{V}$ infusion in $250 \mathrm{ml}$ normal saline (NS) over 30 minutes

Actinomycin D $\quad 0.5 \mathrm{mg} \mathrm{I} / \mathrm{V}$ bolus

Methotrexate $\quad 100 \mathrm{mg} / \mathrm{m}^{2} \mathrm{I} / \mathrm{V}$ bolus followed by $200 \mathrm{mg} / \mathrm{m}^{2} \mathrm{I} / \mathrm{V}$ infusion in $500 \mathrm{ml}$ NS over 12 hours

Day 2

Etoposide

$100 \mathrm{mg} / \mathrm{m}^{2} \mathrm{I} / \mathrm{V}$ infusion in $250 \mathrm{ml}$ normal saline (NS) over 30 minutes

Actinomycin D $0.5 \mathrm{mg} \mathrm{I} / \mathrm{V}$ bolus

Folinic acid $\quad 15 \mathrm{mg} \mathrm{I} / \mathrm{M}$ every 12 hours, 4 doses beginning 24 hours after starting MTX

Course 2: $\mathrm{CO}$

Day 8

Cyclophosphamide $600 \mathrm{mg} / \mathrm{m}^{2} \mathrm{I} / \mathrm{V}$ in $500 \mathrm{ml} \mathrm{NS}$ over 24 hours

Vincristine

$1 \mathrm{mg} / \mathrm{m}^{2} \mathrm{I} / \mathrm{V}$ bolus

In all cases, the cycles were repeated after 7 days interval. The resonse to treatment was evaluated during follow-up by history, clinical examination, serum $\beta$ hCG levels and imaging as and when required. When serum $\beta$ hCG became normal, patient received two more cycles of respective chemotherapy.

\section{RESULTS}

During the study period, total gynaecological admissions were 3277. Of these, 102 (3.1\%) were GTD cases.

Mean age of GTD cases was 25.09 \pm 7.9 years (Range:15-50 years). Parity range is $\mathrm{P}_{0}-\mathrm{P}_{11}$. Characteristics of the patients are depicted in Table 2.

Table 2. Chacacteristics of the patients $(\mathrm{N}=102)$.

\begin{tabular}{|c|c|}
\hline Age (years) & n(\%) \\
\hline$\leq 19$ & $23(22.5)$ \\
\hline $20-29$ & $60(58.8)$ \\
\hline $30-39$ & $9(8.8)$ \\
\hline$\geq 40$ & $10(9.8)$ \\
\hline \multicolumn{2}{|l|}{ Parity } \\
\hline $\mathrm{P}_{\mathrm{o}}$ & $38(37.2)$ \\
\hline $\mathrm{P}_{1}$ & $37(36.2)$ \\
\hline $\mathrm{P}_{2}$ & $14(13.7)$ \\
\hline $\mathrm{P}_{3}$ & $4(3.9)$ \\
\hline$\geq \mathrm{P}_{4}$ & $9(8.8)$ \\
\hline \multicolumn{2}{|c|}{ Clinical presentation } \\
\hline P/V bleeding & $69(67.6)$ \\
\hline $1^{\text {st }}$ trimester & $33(47.8)$ \\
\hline $2^{\text {nd }}$ trimester & $36(52.1)$ \\
\hline USG Diagnosis & $30(29.4)$ \\
\hline $1^{\text {st }}$ trimester & $17(56.6)$ \\
\hline $2^{\text {nd }}$ trimester & $13(43.3)$ \\
\hline Abdominal pain & $2(1.96)$ \\
\hline $\mathrm{CAC}$ & $1(0.98)$ \\
\hline \multicolumn{2}{|c|}{ Histopathology reports } \\
\hline Complete mole & $74(72.5)$ \\
\hline Partial mole & $25(24.5)$ \\
\hline Invasive mole & $3(2.9)$ \\
\hline
\end{tabular}

The ultrasonography (USG) diagnosed cases of GTD were 30(29.4\%), 69(67.6\%) visited emergency room $(\mathrm{ER})$ with per vaginal $(\mathrm{P} / \mathrm{V})$ bleeding, six of them presented with severe anemia requiring blood transfusion. Two cases presented with abdominal pain one at 18 weeks period of gestation (POG) and had chunk of vesicle tissues at cervical os and another at 9 weeks POG, later USG revealed HM. Another 
case had visited comprehensive abortion care (CAC) with USG showing early viable 8 weeks pregnancy and had molar tissues during evacuation.

Among 25 cases of partial molar pregnancy, seven cases presented as incomplete abortion and a case of missed abortion.

All cases were managed by suction and evacuation $(\mathrm{S} / \mathrm{E})$, five of them evacuated outside hospital. Sixtyeight had completed follow-up (F/U) with normal serum $\beta$ hCG and remaining 12 are under $\mathrm{F} / \mathrm{U}$.

\section{GTN}

Twenty-two cases received chemotherapy for persistent gestational trophoblastic tumour (PGTT) (19) and invasive mole(3). Twenty cases fell under low risk score group and two cases under high risk group. (Table 3.)

\section{Table 3. Prognostic Risk Score}

\begin{tabular}{|ll|}
\hline Prognostic Risk Score & n(\%) \\
\hline Low risk score & \\
1 & $4(18.1)$ \\
2 & $7(31.8)$ \\
3 & $1(4.5)$ \\
4 & $5(22.7)$ \\
5 & $2(9.09)$ \\
6 & $1(4.5)$ \\
High risk score & \\
7 & $1(4.5)$ \\
8 & $1(4.5)$ \\
\hline
\end{tabular}

Age, parity and histopathology for chemotherapy are depicted in table 4.

Table 4. GTN patient characteristics.

\begin{tabular}{|ll|}
\hline Age (years) & $\mathbf{n}(\%)$ \\
\hline$\leq 19$ & $3(13.6)$ \\
$20-29$ & $14(63.6)$ \\
$30-39$ & $2(9.09)$ \\
$\geq 40$ & $3(13.6)$ \\
Parity & \\
$\mathrm{P}_{0}$ & $6(27.2)$ \\
$\mathrm{P}_{1}$ & $9(40.9)$ \\
$\mathrm{P}_{2}$ & $3(13.6)$ \\
$\mathrm{P}_{3}$ & $1(4.5)$ \\
$\geq \mathrm{P}_{4}$ & $3(13.6)$ \\
Histopathology report & \\
Complete mole & $14(63.6)$ \\
Partial mole & $5(22.7)$ \\
Invasive mole & $3(13.6)$ \\
\hline
\end{tabular}

GTN was diagnosed in 14/90 (15.5\%) of complete HM and 5/90 (5.5\%) of partial HM.

Under low risk group, two were $>40$ years. Under high risk group, one was 25 years and another 50 years age. All cases of partial and invasive mole and twelve complete mole cases were under low risk group and the other two complete mole under high risk group. (Figure 1)

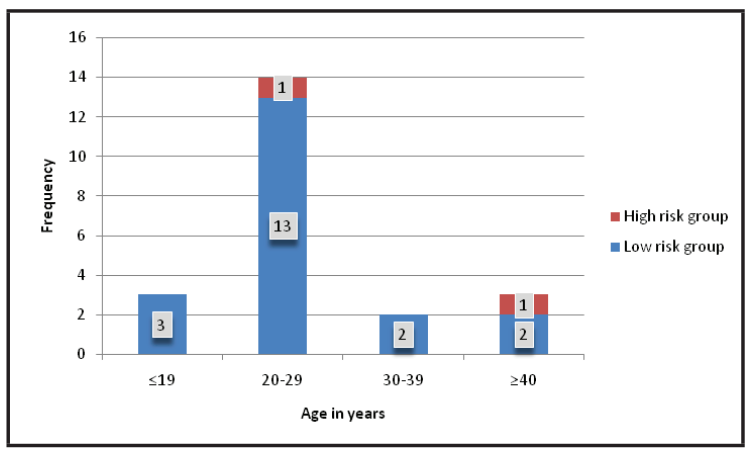

Figure 1. Prognostic Risk Score in relation to age

For low risk group, chemotherapy MTX-FA was started for rising value of serum $\beta$ hCG(13), plateau value(2), persistent vaginal bleeding with rising serum $\beta h C G(2)$, serum $\beta h C G$ not declining six months post-evacuation(1) and invasive mole(3). Among these, five were converted to Act-D for rising value of serum $\beta \mathrm{hCG}(4)$ and plateau value(1). One case converted to EMA-CO as serum $\beta$ hCG began to rise by six-fold with rescoring of high risk.

A case of high risk score group received EMA-CO for increased value of serum $\beta \mathrm{hCG}$.

\section{Response}

Out of 20 low risk cases that received MTX-FA, 13/20 $(65 \%)$ achieved remission. Due to low response of MTX-FA, five of them were converted to Act-D and achieved remission(100\%). Another was converted to EMA-CO with rescoring of high risk and achieved remission with four cycles.

A case of high risk score 8 who had $\mathrm{S} / \mathrm{E}$ for complete mole outside hospital and was lost to $\mathrm{F} / \mathrm{U}$ there, visited to this hospital 12 months following evacuation who had persistent vaginal bleeding and serum $\beta$ hCG $>150,000 \mathrm{mIU} / \mathrm{ml}$ received EMA-CO regimen and achieved remission with eight cycles (100\% remission for EMA-CO). 


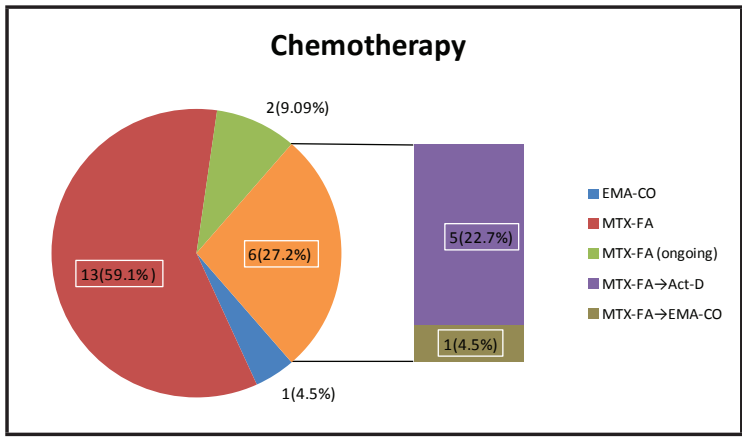

Figure 2. Single agent and multiagent chemotherapy based on prognostic risk score.

\section{Undergoing chemotherapy}

One case of complete mole (low risk score 4) received MTX-FA for rising serum $\beta \mathrm{hCG}$ and completed three cycles so far. Another case of invasive mole 44 years $\mathrm{P}_{10}$ lady underwent total abdominal hysterectomy with bilateral salpingo-ophorectomy (TAH with BSO) for persistent vaginal bleeding and not declining serum $\beta \mathrm{hCG}$ (preevacuation state $>150,000$ $\mathrm{mIU} / \mathrm{ml}$ ) following which serum $\beta \mathrm{hCG}$ declined but later increased by 2-fold, received MTX-FA (low risk score 5) completed six cycles and responding well. Both of these cases are undergoing chemotherapy and $\mathrm{F} / \mathrm{U}$.

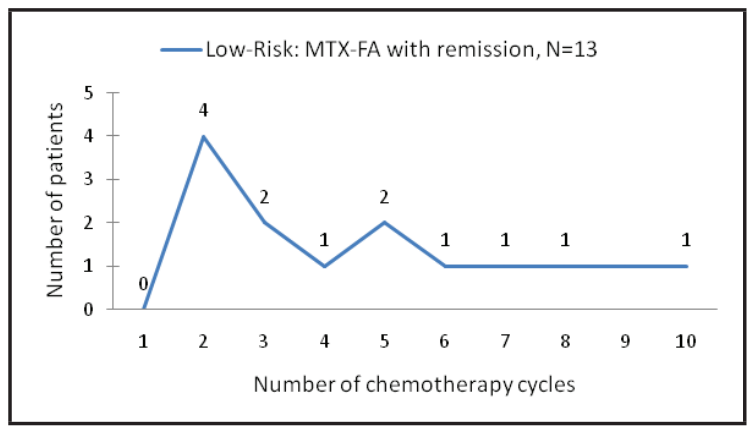

Figure 3. Number of Chemotherapy Cycles for low risk GTN: Remission with MTX-FA

MTX-FA converted to Act-D were five patients after 5, 6 and 12 cycles of MTX-FA each for three patients and after 8 cycles for two patients.

Those converted received Act-D by three patients two cycles each, one cycle by one patient and another one received five cycles.

There was one patient who received five MTX-FA cycles and converted to EMA-CO to receive four cycles after rescoring.

There was one patient with high risk score who received eight cycles of EMA-CO.

\section{DISCUSSION}

The incidence of GTD varies greatly between different parts of the world. Asian ethnicity is an important risk factor for GTD. ${ }^{9}$ In this study, the incidence of GTD was $3.1 \%$. Mean age of GTD cases was $25.09 \pm 7.9$ years (Range:15-50 years). Among 102 cases of GTD, range of parity was from 0 to 11 which was comparable (0 to 17 ) to a study by Fatima et al. ${ }^{10}$

In this study, most of the GTD cases presented as $\mathrm{P} / \mathrm{V}$ bleeding $(67.6 \%)$ which is similar to studies conducted by Fatima et al. ${ }^{10}$ and Hou et al. ${ }^{11}$ USG diagnosed cases of GTN in $29.4 \%$ and more than half of these, $17 / 30(56.6 \%)$ were diagnosed in first trimester, reflecting the diagnosis of disease by USG in early pregnancy. ${ }^{12}$

The risk of GTN for complete HM (15-20\%) is significantly higher than for partial HM $(0.2-4 \%)^{13-}$ ${ }^{16}$ as was also noted in this study CHM (15.5\%) and PHM (5.5\%).

Maternal age is considered as one of the high risk factors for GTN. ${ }^{17}$ In our study, the GTN patients were 18 to 50 years of age and in a study by Fulop et al. ${ }^{18}$ noted the age range of 14 to 53 years. In this study, out of 22 GTN cases, although majority of low risk scored were below 40 years age group (18), other two were $>40$ years. Under high risk group, one was 25 years and another 50 years age. (Figure 1) In a study conducted by Shrivastava et al. ${ }^{19}$ eight out of $27(29.6 \%)$ were aged above 40 years and all were scored as high risk GTN. All low risk cases were aged below 40 years.

Chemotherapy is highly effective in most patients with GTN. For nearly all low risk GTN patients, single agent chemotherapy with either MTX or Act-D is the preferred treatment. ${ }^{1,2,5,7,20} \mathrm{~A}$ variety of regimens have been developed, in which non-randomized, mostly retrospective studies demonstrate a $50-90 \%$ chance of inducing remissiion. ${ }^{21}$ Multiple agent chemotherapy should be used primarily in all high risk GTN patients. The most widely used regimen includes EMA-CO with cure rates ranging from $70 \%$ to $90 \% .^{22}$

In this study, the remission rate of MTX for low risk GTN was $65 \%$ which is similar (66.8\%) to a study conducted by McNeish et al. ${ }^{23}$ In various other studies, MTX remission rate ranged from $81 \%$ to $96.3 \%{ }^{18,24,25}$ The remission rate of Act-D is $96.4 \%$ (Fulop et al.) ${ }^{18}$ and was $100 \%$ in this study. This rate ranged from $75 \%$ to $86.5 \%$ in different other studies. ${ }^{23,24,26}$ These 
variations could be due to different doses used in their studies.

The remission rate of EMA-CO regimen for high risk GTN in this study was $100 \%$. However, different studies reported 71\% (Escobar et al.), ${ }^{27}$ 87.7\% (Bafna et al. $)^{28}$ and $89.4 \%$ (Shrivastava et al.) ${ }^{19}$ which could be due to the presence of widespread metastatic disease in their patients.

A case of invasive mole 44 years $\mathrm{P}_{10}$ lady underwent TAH with BSO for persistent vaginal bleeding and not declining serum $\beta \mathrm{hCG}$ (preevacuation state $>150,000$ $\mathrm{mIU} / \mathrm{ml}$ ) following which serum $\beta \mathrm{hCG}$ declined but later increased by 2-fold, received MTX-FA (low risk score 5) completed six cycles and responding well. Shrivastava ${ }^{19}$ reported TAH in seven patients of low risk and two in high risk patients for different reasons. May et al. ${ }^{2}$ reported 32 patients with low risk GTN treated with hysterectomy and chemotherapy. A hysterectomy may be considered in low risk GTN to reduce multiple doses of chemotherapeutic agents.
Of the 13 low risk GTN cases, majority 4(30.7\%) of them achieved remission with two cycles MTXFA and out of five cases of Act-D, most of them i.e. three achieved remission with two cycles. Two high risk GTN patients treated with EMA-CO achieved remission with four and eight cycles of chemotherapy each. This is comparable with a study conducted by Shivastava et al. ${ }^{19}$ where the low risk patients treated with MTX achieved remission after one cycle, those who were treated with Act-D achieved remission after three cycles and in high risk patients treated with EMA-CO, ten patients achieved remission after three cycles and six patients achieved remission after six cycles.

\section{CONCLUSIONS}

The most common presentation of GTD was vaginal bleeding. Low risk GTN achieved $65 \%$ remission with Methotrexate-Folinic acid, ultimately achieved 100\% remission with Actinomycin-D. High risk GTN achieved 100\% remission with EMA-CO regimen.

\section{REFERENCES}

1. Seckl MJ, Sebire NJ, Fisher RA, Golfier R, Massuger L, Sessa $\mathrm{C}$, et al. Gestational trophoblastic disease: ESMO clinical practice guidelines for diagnosis, treatment and follow-up. Ann Oncol. 2013;24:39-50.

2. May T, Goldstein DP, Berkowitz RS. Current chemotherapeutic management of patients with gestational trophoblastic neoplasia. Chemother Res Pract. 2011;2011:806256.

3. Froeling FE, Seckl MJ. Gestational trophoblastic tumours: an update for 2014. Curr Oncol Rep. 2014;16(11):408.

4. Biscaro A, Braga A, Berkowitz RS. Diagnosis, classification and treatment of gestational trophoblastic neoplasia. Rev Bras Ginecol Obstet. 2015;37(1):42-51.

5. Lurain JR. Gestational trophoblastic disease II: classification and management of gestational trophoblastic neoplasia. Am J Obstet Gynecol. 2011;204(1):11-8.

6. FIGO Oncology Committee. FIGO staging for gestational trophoblastic neoplasia 2000. Int J Gynaecol Obstet. 2002;77(3):285-7.

7. Ngan HY, Kohorn EI, Cole LA, Kurman RJ, Kim SJ, Lurain JR, et al. FIGO report 2012: trophoblastic disease. Int J Gynaecol Obstet. 2012;119(2):130-36.

8. FIGO Committee on Gynecologic Oncology. Current FIGO staging for cancer of the vagina, fallopian tube, ovary, and gestational trophoblastic neoplasia. Int $\mathrm{J}$ Gynaecol Obstet. 2009 Apr. 105(1):3-4

9. Gestational trophoblastic disease: Epidemiology, clinical manifestations and diagnosis. Chiang JW, Berek JS. In: UpToDate [Textbook of Medicine]. Basow, DS (Ed). Massachusetts Medical Society, Waltham, Massachusetts, USA, and Wolters Kluwer Publishers, Amsterdam, The Netherlands. 2010

10. Fatima M, Kasi PM, Baloch SN, Kassi M, Marri SM. Incidence, Management, and Outcome of Molar Pregnancies

at a Tertiary Care Hospital in Quetta, Pakistan. ISRN Obstet Gynecol. 2011;2011:925316.

11. Hou JL, Wan XR, Xiang Y, Qi QW, Yang XY. Changes of clinical features in hydatidiform mole: analysis of 113 cases. J Reprod Med. 2008;53(8):629-33

12. Benson CB, Genest DR, Bernstein MR, Soto-Wright N, Goldstein DP, Berkowitz RS. Sonographic appearance of first trimester complete hydatidiform moles. J Ultrasound Obstet Gynecol. 2000;16(2):188-91.

13. Feltmate CM, Growdon WB, Wolfberg AJ, Goldstein DP Genest DR, Chinchilla ME, et al. Clinical characteristics of persistent gestational trophoblastic neoplasia after partial hydatidiform molar pregnancy. J Reprod Med. 2006;51(11):902-906.

14. Hancock BW, Nazir K, Everard JE. Persistent gestationa trophoblastic neoplasia after partial hydatidiform mole incidence and outcome. J Reprod Med. 2006;51:764-66.

15. Sebire NJ, Fisher RA, Foskett M, Rees H, Seckl M, Newlands Risk of recurrent hydatidiform mole and subsequent pregnancy outcome following complete or partial hydatidiform molar pregnancy. BJOG. 2003;110(1):22-26.

16. Wielsma S, Kerkmeijer L, Bekkers R, Pyman J, Tan J. Persistent trophoblast disease following partial molar pregnancy. Aust N Z J Obstet Gynaecol. 2006;46:119-23.

17. Berkowitz RS, Goldstein DP. Gestational Trophoblastic Neoplasia. In: Berek JS, Hacker NF, editors. Practical Gynecologic Oncology. Baltimore: Williams and Wilkins; 1989. pp. 441-68

18. Fulop V, Szigetvari I, Szepesi J, Vegh G, Batorfi J, Nagymanyoki Z, Torok M, Berkowitz RS. 30 years' experience in the treatment of low-risk gestational trophoblastic neoplasia in Hungary. J Reprod Med. 2010;55(5-6):253-57. 
19. Shrivastava S, Kataki AC, Barmon D, Deka P, Bhuyan C, Bhargav SJ. Gestational trophoblastic neoplasia: A 6 year retrospective study. South Asian J Cancer. 2014;3(1):33-37.

20. Growdon WB, Wolfberg AJ, Goldstein DP, Feltmate CM, Chinchilla ME, Lieberman ES, et al. Evaluating methotrexate treatment in patients with low-risk postmolar gestational trophoblastic neoplasia. Gynecol Oncol. 2009;112(2):353-57.

21. Alazzam M, Tidy J, Hancock BW, Osborne R, Lawrie TA First-line chemotherapy in low-risk gestational trophoblastic neoplasia. Cochrane Database Syst Rev. 2012;7:CD007102.

22. Lurain JR, Singh DC, Schink JC. Primary treatment of metastatic high risk gestational trophoblastic neoplasms with EMA-CO chemotherapy. J Reprod Med. 2006;51:767-72.

23. McNeish IA, Strickland S, Holden L, Rustin GJ, Fosket M, Seckl MJ, Newlands ES. Low-risk persistent gestational trophoblastic disease: outcome after initial treatment with low-dose methotrexate and folinic acid from 1992 to 2000. J Clin Oncol. 2002;20(7):1838-44

24. Chapman-Davis E, Hoekstra AV, Rademaker AW, Schink JC, Lurain JR. Treatment of nonmetastatic and metastatic lowrisk gestational trophoblastic neoplasia: factors associated with resistance to single-agent methotrexate chemotherapy. Gynecol Oncol. 2012;125(3):572-75.

25. Gilani MM, Fariba B, Behtash N, Ghaemmghami F, Moosavi AS, Rezayof E. The WHO score predicts treatment outcome in low risk gestational trophoblastic neoplasia patients treated with weekly intramuscular methotrexate. J Cancer Res Ther. 2013;9(1):38-43

26. Lurain JR, Chapman-Davis E, Hoekstra AV. Schink JC. Actinomycin D for methotrexate-failed low-risk gestational trophoblastic neoplasia. J Reprod Med. 2012;57(7-8):283-87.

27. Escobar PF, Lurain JR, Singh DK, Bozorgi K, Fishman DA. Treatment of high-risk gestational trophoblastic neoplasia with etoposide, methotrexate, actinomycin D, cyclophosphamide, and vincristine chemotherapy. Gynecol Oncol. 2003;91(3):552-57.

28. Bafna UD, Ahuja VK, Umadevi K, Srinivasan N, Mani K, Vallikad E. Gestational trophoblastic tumors - situation analysis in a third world regional cancer center. Int J Gynecol Cancer. 1997;7:197-204. 